\title{
Article \\ Comparison between Digital Casts and Cone Beam Computed Tomography for Measuring Maxillary Transverse Dimensions in Patients with Impacted Canines
}

\author{
Elena Martinez Madero ${ }^{1, *}$, Jaime García Montarelo ${ }^{1}$, Grace Stefany Aguayo ${ }^{1}$ and Conchita Martin ${ }^{1,2} \mathbb{D}$ \\ 1 Department of Orthodontics, Faculty of Odontology, Complutense University of Madrid, 28040 Madrid, \\ Spain; jaime.garcia.montarelo@gmail.com (J.G.M.); elena_mm21@hotmail.com (G.S.A.); \\ conchitamartin@odon.ucm.es (C.M.) \\ 2 BIOCRAN (Craniofacial Biology: Orthodontics and Dentofacial Orthopedics) Research Group, \\ Complutense University of Madrid, 28040 Madrid, Spain \\ * Correspondence: elenammadero@gmail.com; Tel.: +34-65-9105174
}

check for updates

Citation: Martinez Madero, E.; García Montarelo, J.; Aguayo, G.S.; Martin, C. Comparison between Digital Casts and Cone Beam Computed Tomography for Measuring Maxillary Transverse Dimensions in Patients with Impacted Canines. Children 2022, 9, 278. https://doi.org/10.3390/ children 9020278

Academic Editors: Gianluca M. Tartaglia, Santosh K. Tadakamadla and Loc Do

Received: 10 January 2022

Accepted: 8 February 2022

Published: 17 February 2022

Publisher's Note: MDPI stays neutral with regard to jurisdictional claims in published maps and institutional affiliations.

Copyright: (C) 2022 by the authors. Licensee MDPI, Basel, Switzerland. This article is an open access article distributed under the terms and conditions of the Creative Commons Attribution (CC BY) license (https:// creativecommons.org/licenses/by/ $4.0 /)$.

\begin{abstract}
Cone beam computed tomography (CBTCT) scans $(n=45)$ and digital dental casts $(n=45)$ were both used to measure the maxillary transverse dimensions in patients with impacted maxillary canines. The objectives were to explore the associations of these dimensions with the impaction and patient characteristics, and to compare the measurements between these techniques. The maxillary width was measured on scans and casts at the Walaridge, and the intermolar width and interpremolar width levels were measured at the first and second premolars (measured from the buccal grooves and the palatal cuspids, and the palatal and lingual amelocemental junctions). Two examiners independently compared the measurements between the control quadrants (without impaction) and the case quadrants (with impaction) in patients with unilateral impactions, and between the unilateral and bilateral impaction groups. The interclass correlation coefficient (ICC) was calculated to assess the interexaminer reliability and paired or independent Student's $t$-tests and ANOVAs were used for comparisons. The ICCs were 0.887 and 0.919 , globally, for the measurements on the CBCT scans and casts, respectively, which indicates the excellent interexaminer reliability. On the CBCT scans, statistically significant differences were found between the case and control quadrants in the transverse measurements at the lingual level on the upper first molars, and at the WALA ridge level on the upper second premolars $(p<0.05)$ in the unilateral impaction group. Significant differences were found between the case quadrants in the unilateral versus the bilateral groups at the WALA ridge on the second premolars in casts $(p<0.05)$, and at the lingual point on the first molars on the CBCT scans $(p<0.05)$. No statistically significant differences in the transverse measurements were observed between the impacted buccal and palatal canines on either the casts or CBCT scans. To the best of our knowledge, this is the first study to compare the transverse measurements between digital models and CBCT scans.
\end{abstract}

Keywords: included canines; canine impaction; maxillary transverse dimension; CBCT transversal measurements; dental cast maxillary measurements; intermolar width; interpremolar width; Walaridge

\section{Introduction}

The maxillary canines are the second most frequently impacted teeth after the third molars [1]. The etiology of their impaction is associated with local (high canine position in the maxillary arch and maxillary transverse dimension; and the agenesis, or microdontia, of the lateral incisors) and genetic factors [2-4]. Buccal canine displacement is most often associated with anterior maxillary transverse (dental and skeletal) deficiency and palatal displacement, with small or missing lateral incisors, which is consistent with the guidance theory [5]. 
Various authors have reported that patients with canine impactions have a maxillary transverse deficiency in the anterior portion of the dental arch, and that premaxillary skeletal deficiency is frequently associated with the buccal impaction of the maxillary canines $[3,6]$. It has also been observed that maxillary transverse excess can be associated with their palatal impaction [7], while another study found a narrower and longer maxillary arch in patients with palatal versus buccal impacted canines [5]. In contrast, Langberg concludes that the maxillary arch width is not a primary contributory factor in the genesis of palatal displaced canines (PDCs) [8], and Saiar et al. assert that the maxillary intercanine alveolar arch width is not a good predictor of PDCs [9]. Likewise, Yan et al. found that PDCs are largely associated with small or missing lateral incisors, which is in line with the guidance theory [10].

No consensus has been established on the best approach to maxillary transverse deficiency measurement [11]. Digital dental casts have been used for maxillary transverse measurements in patients with impacted canines by most authors [9,12-14], and cone beam computed tomography (СBCT) scans by others [15-18]. Hong et al. measured the maxillary basal bone and the interdental widths at the maxillary first molars and the first and second premolars on the axial and coronal CBCT sections [15], and Arboleda recorded measurements on images at four levels: at the first molar basal and alveolar widths, and at the first premolar basal and alveolar widths [16]. Cacciatore, Ghaffar, and Kim used digital dental casts to measure the maxillary dentoalveolar width, which is defined as the distance between the mesiobuccal cusp tips of the first molars $[7,13,19]$, whereas Bizarro considered the intercanine and intermolar widths at the cusp and gingival levels [12]. In their study, Saiar et al. measured the maxillary intermolar width as the distance between the central grooves on the permanent maxillary first molars [9].

There has been little high-quality research on the maxillary transverse deficiencies and the results have been controversial, with some studies reporting that the arch width prediction indices obtained from the dental cast measurements are undependable. Measurement on CBCT images has been described as a more reliable diagnostic approach, but further validation is required to confirm its accuracy. No study has addressed the maxillary morphology using both digital dental casts and CBCTs.

In this study, digital dental casts and CBCT scans were both used to measure the maxillary dental arch transverse dimensions in patients with impacted canines. The study objectives were to explore the associations of these dimensions with the impaction and patient characteristics, and to compare the measurements between these techniques, with the aim of contributing to the development of standardized procedures for these measurements.

\section{Materials and Methods}

\subsection{Subjects and Study Design}

This is a transversal analytical study. The study sample was recruited from among the patients attending the Orthodontics Department Clinic at the Complutense University of Madrid (UCM) from 2005 through to 2021. Th study inclusion criteria were: (1) Aged over 11 years and cervical vertebral maturation (a CVM less than 4) [20]; (2) The presence of mixed or permanent dentition; (3) A sagittal discrepancy $<3 \mathrm{~mm}$ with no need for extraction (nonextraction case); (4) A vertical overbite $>3 \mathrm{~mm}$, but $<6 \mathrm{~mm}$; and (5) A transverse maxillomandibular discrepancy $<4 \mathrm{~mm}$ (nonsurgical case). The study exclusion criteria were: (1) A history of systematic disease and/or medication affecting the tooth movement or the bone metabolism; (2) Orofacial malformation syndrome; (3) A history of treatment with orthodontic/orthopedic appliances; (4) A defect in the X-ray or casts that could affect the measurements; and (5) An ankylosed canine (i.e., no movement after three months of treatment). The sample size estimation was based on a previous study by Cacciatore et al. (2018) [19], in which the mean difference between the affected and unaffected sides was $0.32 \mathrm{~mm}$, with a SD of $0.44 \mathrm{~mm}$. Setting an alpha significance level of 0.05 and a beta significance level of 0.10 , for a power of $90 \%$, to detect the intragroup 
differences, we concluded that 23 patients were needed in each group. A total of 50 patients were finally enrolled in order to cover the possible dropouts.

\subsection{Methodology of Measurements}

For the measurements, the transverse width of the maxillary arch was divided between the control quadrant (without impaction) and the case quadrant (with impaction) in the patients with unilateral impactions, whereas both hemiarches were considered case quadrants in the patients with bilateral impactions. The total transverse widths were also compared between the unilateral and bilateral impactions, and between the buccal and palatal displacement. All the measurements were independently performed by two examiners (E.M. and J.G.).

For the measurements in the digital casts and CBCT scans, a modified method based on a combination of other studies by Hong et al. and Cacciatori et al. was used [15,19].

The study model casts were scanned using a 3D scanner (3Shape D700, Copenhagen, Denmark), with a reported accuracy of $<20$ microns (www.3shape.com, last accessed on 10 February 2022), which imported the 3D data into the OrthoAnalyzer software package (3Shape Systems, Inc. Copenhagen, Denmark). The authors used the alginate, Orthoprint (Zhermarck ${ }^{\circledR}$, Rovigo, Italy), to make the impressions of the patients, as well as Type III plaster (Orthoguix plaster, Protechno ${ }^{\circledR}$, Girona, Spain). The measurements were made from four points on the first molars and the first and second premolars: from the gingival level of the mesiopalatal cuspid, and from the central groove, the mesiobuccal cuspid, and the Walaridge point. The distances were measured from each point to the medial sagittal plane (i.e., perpendicular to the occlusal plane that crosses the palatine raphe (the posterior and medial points of the raphe)). The final measurements were the distances from the gingival level to the medial sagittal plane, from the central groove to the medial sagittal plane, from the mesiobuccal cuspid (buccal cuspid in premolars) to the medial sagittal plane, and from the Walaridge to the medial sagittal plane (Figures 1-4).

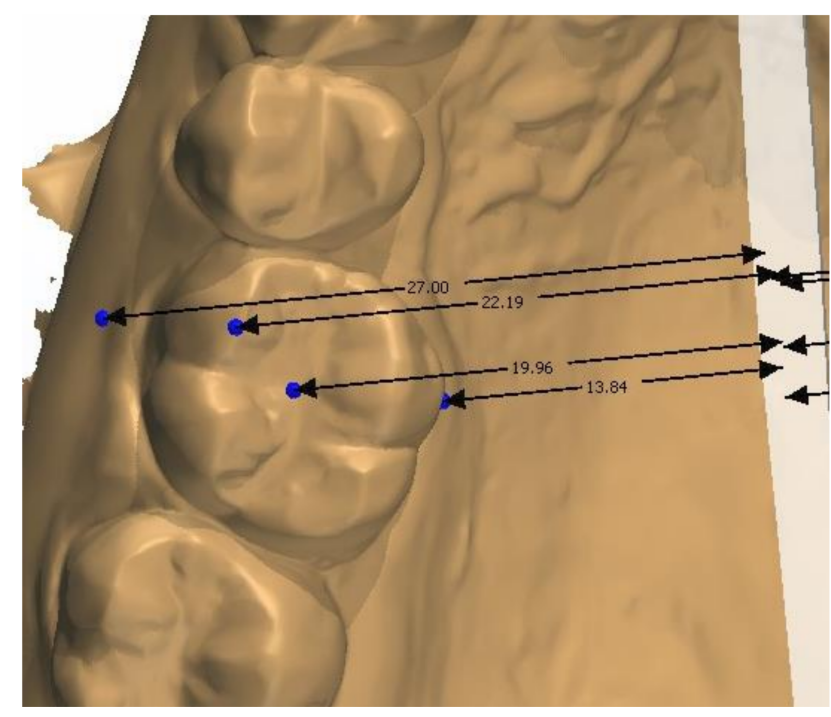

Figure 1. Points on first molars on digital casts. 


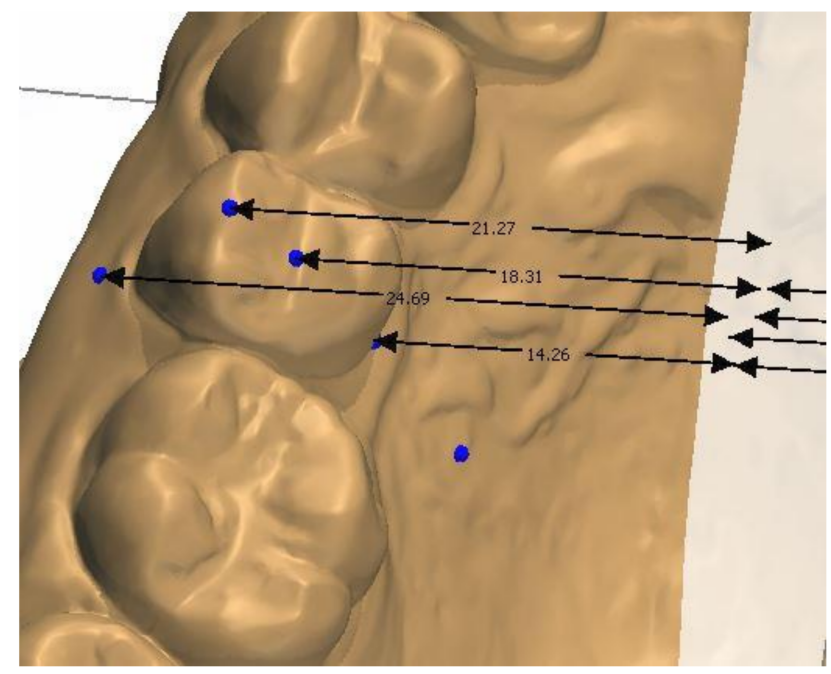

Figure 2. Points on second premolars on digital casts.

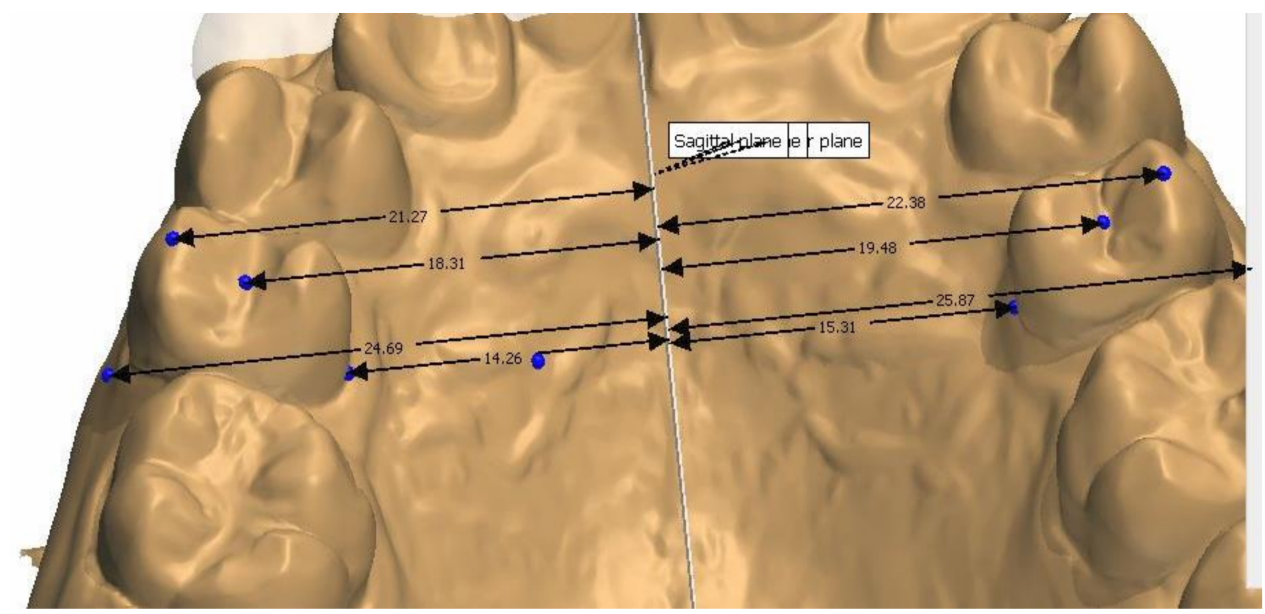

Figure 3. Distances from second premolar to medial sagittal plane.

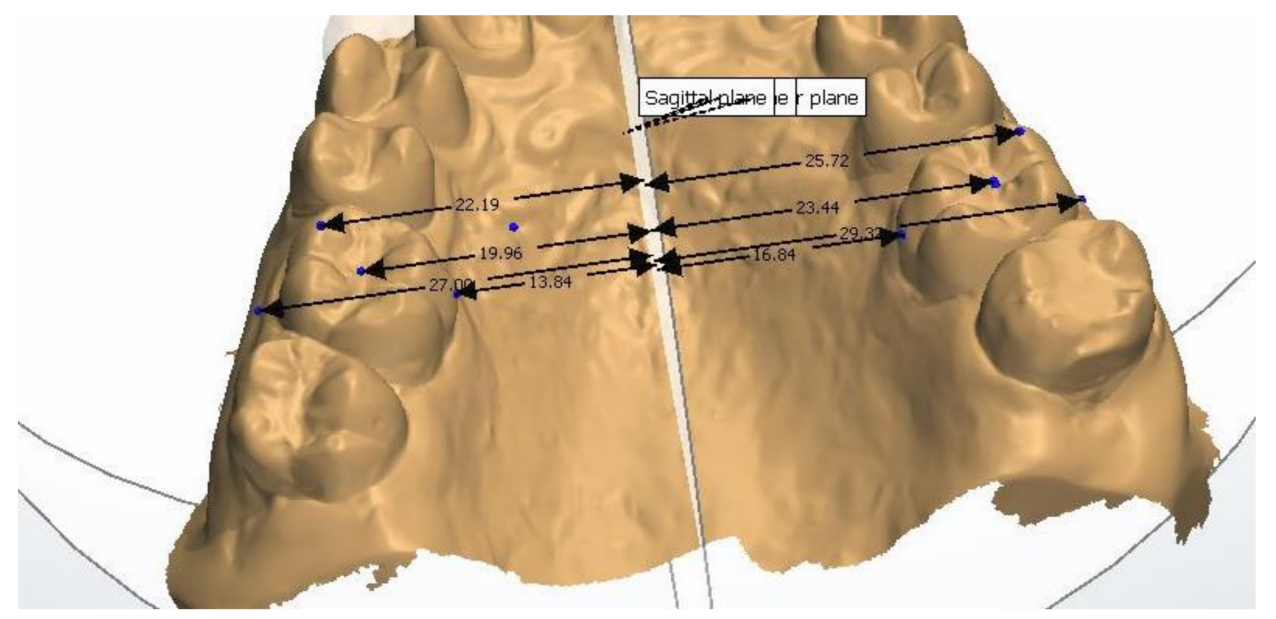

Figure 4. Distances from first molar to medial sagittal plane.

The CBCT data were obtained using the i-CAT ${ }^{\circledR}$ Cone Beam 3D Imaging System (Imaging Sciences International, Inc., Hatfield, PA, USA), with the patients in an upright position, and always using the same machine and parameters: a $17-\mathrm{cm} \times 23-\mathrm{cm}$ field of view, $120 \mathrm{kV}, 5 \mathrm{~mA}$ (pulsed mode), and a $0.3-\mathrm{mm}$ voxel size. The measurements were made 
from six points on the first molars and the first and second premolars: the palatal cuspid, the buccal cuspid, the lingual gingival, the buccal gingival (amelocemental junction), the central groove, and the Walaridge. The distances were measured from each point to the medial sagittal plane (Figures 5 and 6). The skeletal transverse distance was also measured as the distance between the J point and the sagittal medial plane (Figure 7).

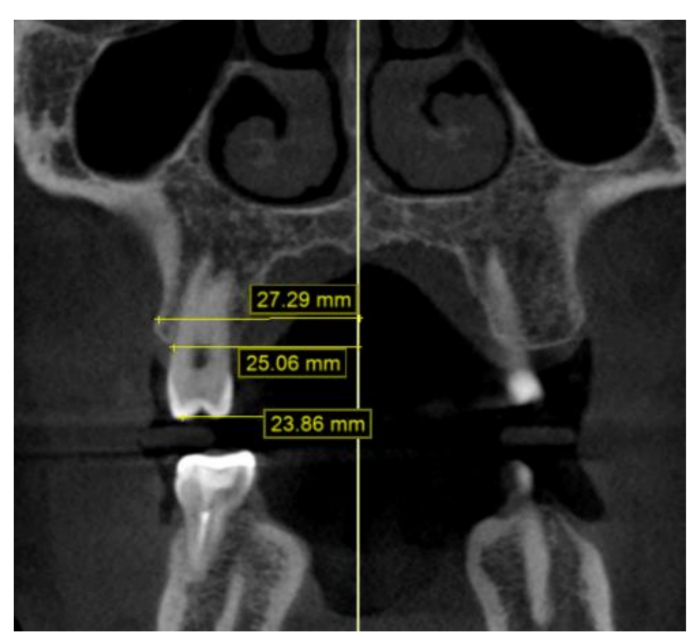

Figure 5. Distances from second premolar to medial sagittal plane on CBCT scan: Walaridge, gingival buccal level, and buccal cuspid.

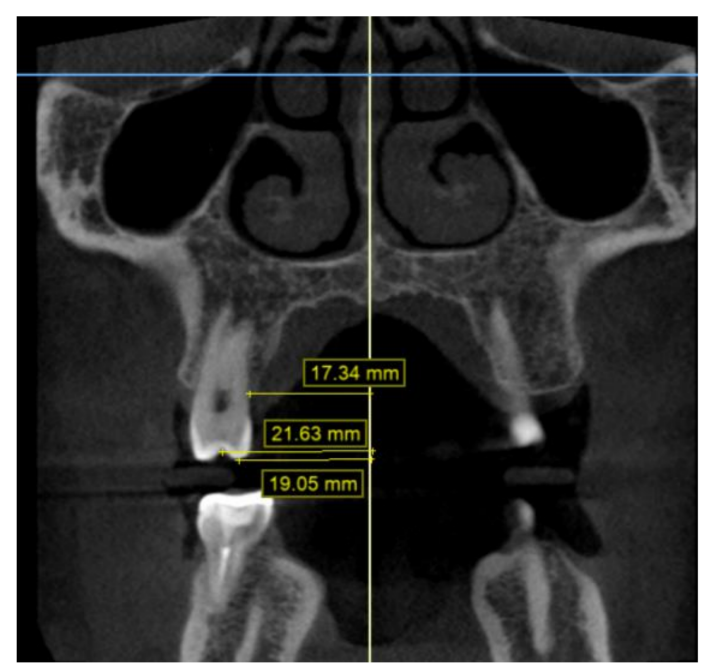

Figure 6. Distances from second premolar to medial sagittal plane on CBCT scan: groove, lingual gingival, and palatal cuspid. 


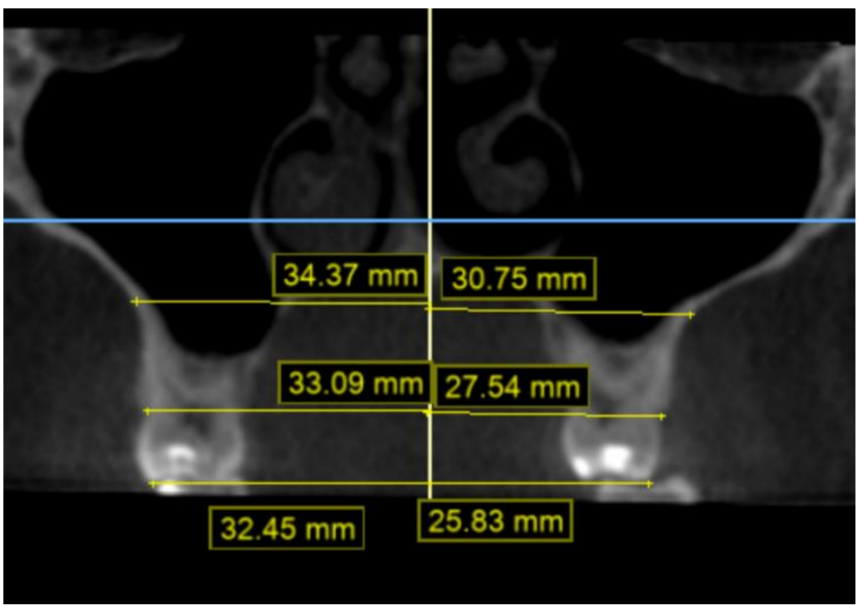

Figure 7. Distances from first molar to median sagittal plane on CBCT scan: Walaridge, groove, and J point.

\subsection{Statistical Analysis}

Means and standard deviations were calculated for each measurement. The interclass correlation coefficient (ICC) was used to assess the interexaminer agreement. After checking the normality of the data distribution with the Levene's test, Student's $t$-tests and analyses of variance (ANOVAs) were performed to analyze the relationships between the study variables, as specified in the table footnotes. SPSS version 25.0 (IBM Corp, Armonk, NY, USA) was used for the data analyses, which considered $p<0.05$ as significant.

\section{Results}

\subsection{Demographic Data}

Out of the 50 patients enrolled in the study, 5 were excluded for the poor quality of the X-rays or the casts, which left a final study sample of 45 patients ( 25 females and 20 males), with a total of 63 impacted maxillary canines. The mean $( \pm \mathrm{SD})$ age was $15.42 \pm 3.42$ years (Table 1), and all of the participants had mixed or permanent dentition and cervical vertebral maturation at Stages 4 or 5 . No significant differences in the study variables were observed between the sexes, or as a function of the patient age, the palatal/buccal displacement, or the unilateral/bilateral impaction (Table 1) (Figure 8). The ICC index for the interexaminer agreement was 0.919 for the cast measurements, and 0.887 for the CBCT measurements, which are, i.e., almost perfect correlations (Table 2).

Table 1. Patient characteristics: sex, palatal/buccal localizations of the impactions, and their unilateral or bilateral type.

\begin{tabular}{cccccc}
\hline \multirow{2}{*}{ Gender } & \multicolumn{2}{c}{ Impaction Localization } & \multicolumn{2}{c}{ Type of Impaction } & Age (Years) \\
\cline { 2 - 6 } & Palatal & Buccal & Unilateral & Bilateral & $\boldsymbol{\mu} \pm$ SD \\
\hline Male & 13 & 7 & 16 & 6 & $15.61 \pm 3.42$ \\
Female & 17 & 8 & 21 & 7 & $14.66 \pm 4.20$ \\
TOTAL & 30 & 15 & 34 & 11 & \\
$p$ value & & 0.504 & & & 0.554 \\
\hline
\end{tabular}

Table 2. Interclass coefficients for interexaminer agreement.

\begin{tabular}{cccc}
\hline $\begin{array}{c}\text { Interclass Coefficients for } \\
\text { Interexaminer Agreement }\end{array}$ & Median & Max & Min \\
\hline Casts & 0.919 & 0.997 & 0.54 \\
CBCT scans & 0.887 & 0.988 & 0.32 \\
\hline
\end{tabular}




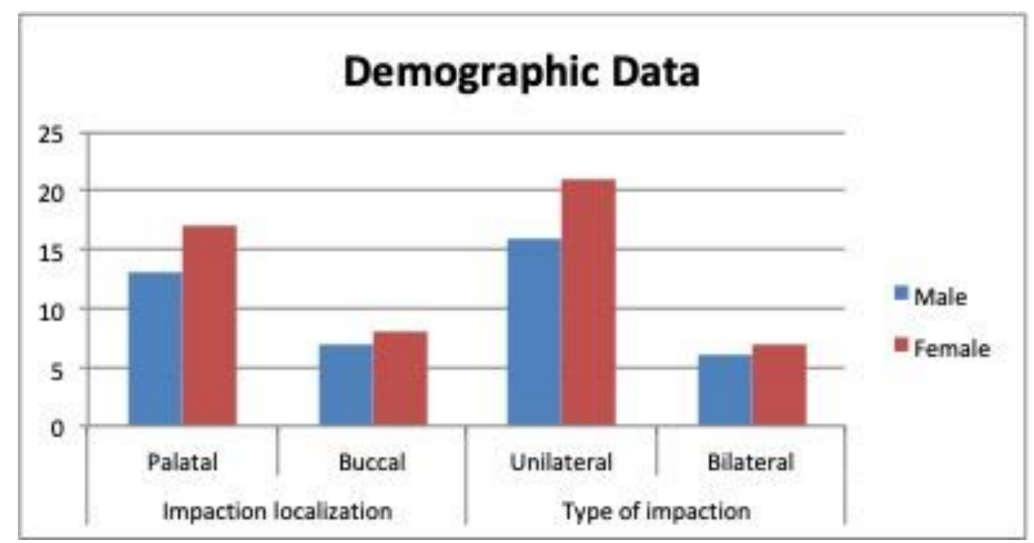

Figure 8. Patient characteristics: sex, palatal/buccal localizations of the impactions, and their unilateral or bilateral type.

\subsection{Transverse Width}

Unilateral impactions: In the digital models, no significant differences in the transverse widths were found between the case and control quadrants in the unilateral cases. On the $\mathrm{CBCT}$ scans, the intermolar width at the lingual gingival level (mean $\pm \mathrm{SD}$ of $17.01 \pm 1.96 \mathrm{~mm} / \mathrm{SD}=1.96 ; p<0.001)$, and the interpremolar width at the WALA ridge level, were significantly narrower in the case versus the control quadrants (Tables 3 and 4) and (Figures 9 and 10).

Table 3. Comparison of cast measurements between the case and control quadrants in patients with unilateral impactions.

\begin{tabular}{ccccc}
\hline Tooth & Parameter & $\begin{array}{c}\text { Control } \\
\text { Quadrants }\end{array}$ & Case Quadrants & $p$ Value * \\
\hline \multirow{3}{*}{ First Molar } & CG & 22.78 & 23.4 & 0.103 \\
& GL & 16.4 & 16.54 & 0.671 \\
& MBC & 24.94 & 25.28 & 0.343 \\
Second & W & 28.56 & 28.87 & 0.286 \\
Premolar & GG & 20.07 & 19.9 & 0.56 \\
& GL & 15.56 & 15.65 & 0.758 \\
& MBC & 22.5 & 22.57 & 0.798 \\
First & W & 25.86 & 25.95 & 0.65 \\
\hline Premolar & CG & 17.53 & 17.35 & 0.506 \\
& GL & 13.27 & 13.26 & 0.935 \\
& MBC & 19.97 & 20 & 0.919 \\
\hline Student'st-test for paired samples. GL: gingival level; CG: central groove; MBC: mesiobuccal cuspid: W: Walaridge.
\end{tabular}
* $p<0.05$ as significant.

Bilateral impactions: In the digital models, the interpremolar width at the buccal cuspid level on the second premolars was narrower in the patients with bilateral versus unilateral impactions $(21.07 \mathrm{~mm} / \mathrm{SD}=1.58 ; p=0.025)$. The Bonferroni comparisons showed statistically significant differences between the quadrants in the bilateral group and the case quadrants in the unilateral group $\left(p=0.027^{*}\right)$, with a mean difference of $1.59 \mathrm{~mm}(95 \%$ CI, 0.14-3.04) (Table 5), (Figure 11). 
Table 4. Comparison of CBCT measurements between the case and control quadrants in patients with unilateral impactions.

\begin{tabular}{ccccc}
\hline Tooth & Parameter & Control Quadrants & Case Quadrants & $p$ Value * \\
\hline \multirow{3}{*}{ First Molar } & CG & 22.3 & 22.69 & 0.265 \\
& LG & 19.44 & 17.01 & $\mathbf{0 . 0 0 1}$ \\
& PC & 19.31 & 19.69 & 0.281 \\
& BG & 27 & 26.99 & 0.956 \\
& BC & 25.94 & 26.41 & 0.162 \\
& W & 28.72 & 28.86 & 0.642 \\
\hline \multirow{5}{*}{ Second } & CG & 19.6 & 19.89 & 0.303 \\
Premolar & LG & 15.83 & 16.23 & 0.175 \\
& PC & 16.98 & 17.08 & 0.771 \\
& BG & 23.48 & 24.07 & 0.158 \\
& BC & 22.72 & 22.73 & 0.984 \\
First & W & 25.29 & 25.77 & $\mathbf{0 . 0 4 8}$ \\
\hline Premolar & CG & 17.51 & 17.4 & 0.724 \\
& LG & 13.55 & 13.51 & 0.882 \\
& PC & 14.63 & 14.63 & 0.99 \\
& BG & 21.47 & 21.39 & 0.852 \\
& BC & 20.22 & 20.11 & 0.746 \\
& W & 22.16 & 22.54 & 0.163 \\
\hline
\end{tabular}

Student's $t$-test for paired samples; the statistically significant differences are in bold. LG: lingual gingival; CG: central groove; PC: palatal cuspid; BG: buccal gingival; BC: buccal cuspid; and W: Walaridge. * Statistically significant $p \leq 0.05$.

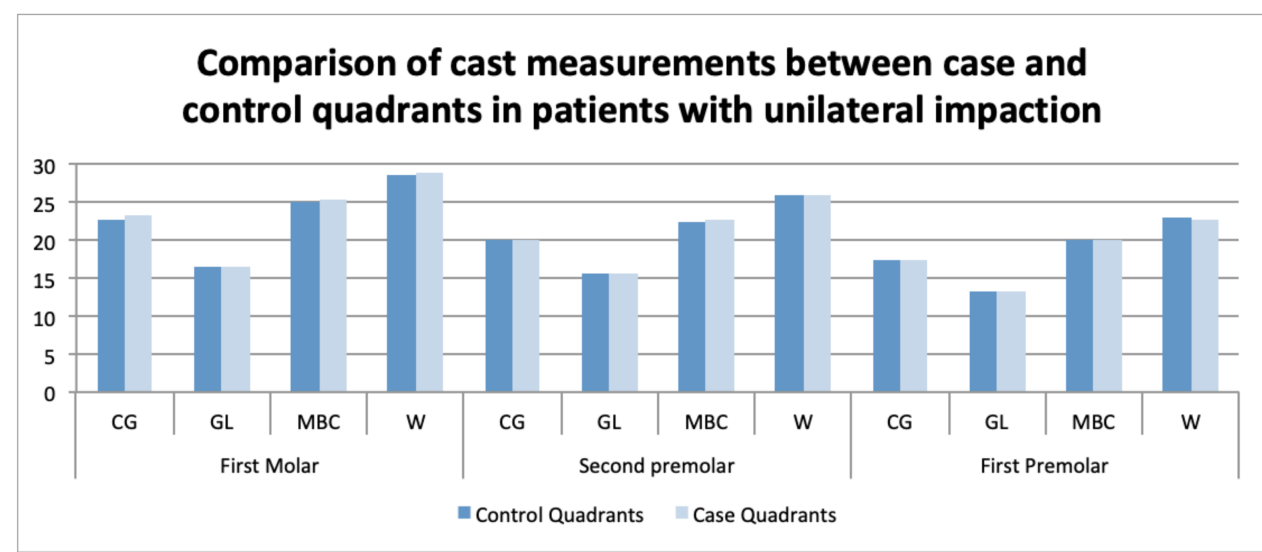

Figure 9. Comparison of cast measurements between the case and control quadrants in patients with unilateral impactions.

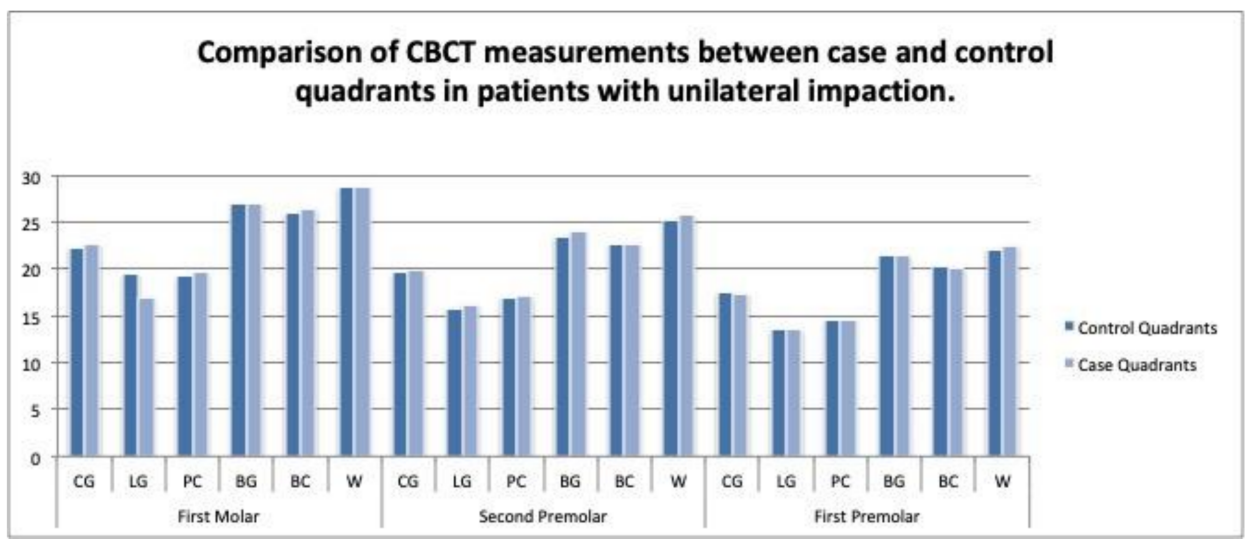

Figure 10. Comparison of CBCT scan measurements between the case and control quadrants in patients with unilateral impactions. 
Table 5. Comparison of cast measurements among the control quadrants and case quadrants in unilateral impactions, and the quadrants in bilateral impactions.

\begin{tabular}{cccccc}
\hline Tooth & Parameter & $\begin{array}{c}\text { Control } \\
\text { Quadrants }\end{array}$ & $\begin{array}{c}\text { Case } \\
\text { Quadrants }\end{array}$ & $\begin{array}{c}\text { Bilateral } \\
\text { Impactions }\end{array}$ & $p$ Value * \\
\hline \multirow{3}{*}{ First Molar } & CG & 22.78 & 23.39 & 22.17 & 0.145 \\
& GL & 16.39 & 16.53 & 15.64 & 0.267 \\
& MBC & 24.94 & 25.27 & 25.17 & 0.456 \\
Second & W & 28.56 & 28.87 & 27.66 & 0.456 \\
Premolar & GG & 20.07 & 19.9 & 18.78 & 0.069 \\
& GL & 15.56 & 15.65 & 14.42 & 0.76 \\
& GC & 22.5 & 22.57 & 21.07 & $\mathbf{0 . 0 2 5}$ \\
First & W & 25.86 & 25.95 & 25.93 & 0.145 \\
\hline Premolar & GG & 17.53 & 17.35 & 16.84 & 0.487 \\
& GL & 13.27 & 13.26 & 12.87 & 0.716 \\
& BC & 19.97 & 20 & 19.28 & 0.373 \\
\hline
\end{tabular}

ANOVA; statistically significant difference $(p \leq 0.05)$ is in bold. GL: gingival level; CG: central groove; MBC: mesiobuccal cuspid; BC: buccal cuspid; W: Walaridge. * Statistically significant $p \leq 0.05$.

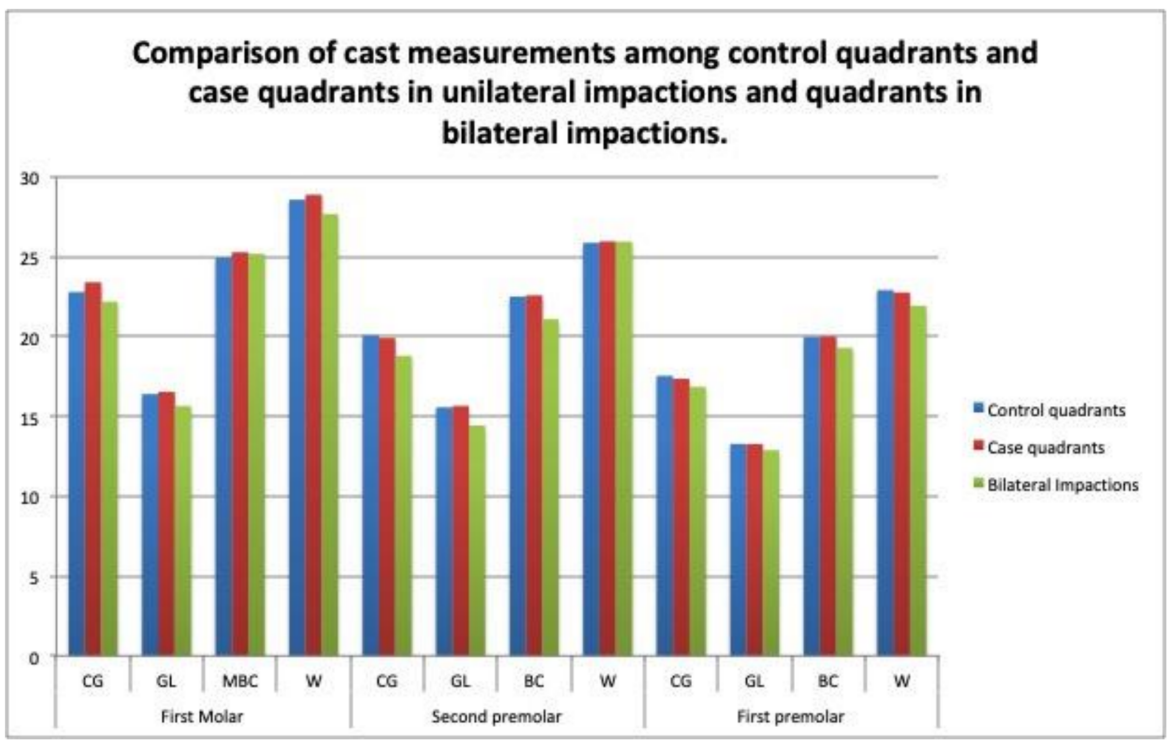

Figure 11. Comparison of cast measurements among the control quadrants and the case quadrants in the unilateral impactions, and the quadrants in the bilateral impactions.

On the $\mathrm{CBCT}$ scans, a narrower intermolar width was found at the lingual gingival level (difference of $16.29 \pm 1.15 \mathrm{~mm} ; p<0.001)$ and the Walaridge level $(21.07 \pm 1.45 \mathrm{~mm}$; $p=0.05)$ on the first premolars in the bilateral versus unilateral impaction cases. The Bonferroni comparisons revealed statistically significant differences in the intermolar width at the gingival level $(p<0.001)$, and in the interpremolar width at the Walaridge level (difference of $1.46 \mathrm{~mm}\left(95 \% \mathrm{CI}, 0.01\right.$ to $\left.2.92 ; p=0.047^{*}\right)$ ) between the quadrants in the bilateral impaction group, and the case quadrants in the unilateral group. Significant differences were also found in the intermolar distance at the gingival level (mean difference of $3.04 \mathrm{~mm}(95 \%$ CI 1.73 to $4.36 ; p<0.001)$ ) between the quadrants in the bilateral impaction group and the case quadrants in the unilateral group, and in the intermolar distance at the gingival level between the case and control quadrants in the unilateral impactions (difference of $2.39 \mathrm{~mm}(95 \% \mathrm{CI}, 1.29$ to $3.48 ; p<0.001)$ ) (Table 6), (Figure 12). 
Table 6. Comparison of CBCT measurements among control quadrants and case quadrants in unilateral impactions, and quadrants in bilateral impactions.

\begin{tabular}{cccccc}
\hline Tooth & Parameter & $\begin{array}{c}\text { Control } \\
\text { Quadrants }\end{array}$ & $\begin{array}{c}\text { Case } \\
\text { Quadrants }\end{array}$ & $\begin{array}{c}\text { Bilateral } \\
\text { Group }\end{array}$ & $p$ Value * \\
\hline \multirow{5}{*}{ First Molar } & CG & 22.3 & 22.69 & 21.86 & 0.231 \\
& LG & 19.44 & 17.01 & 16.29 & $\mathbf{0 . 0 0 1}$ \\
& PC & 19.31 & 19.69 & 19.16 & 0.556 \\
& BG & 27 & 26.99 & 25.9 & 0.093 \\
& BC & 25.94 & 26.41 & 25.77 & 0.413 \\
Second & W & 28.72 & 28.86 & 27.94 & 0.375 \\
& CG & 19.6 & 19.89 & 19.17 & 0.427 \\
& LG & 15.83 & 16.23 & 32.05 & 0.208 \\
& PC & 16.98 & 17.08 & 15.22 & 0.914 \\
Fremolar & BG & 23.48 & 24.07 & 23.35 & 0.587 \\
& BC & 22.72 & 22.73 & 22.05 & 0.399 \\
& W & 25.29 & 25.77 & 24.65 & 0.208 \\
\hline & CG & 17.51 & 17.4 & 16.61 & 0.204 \\
& LG & 13.55 & 13.51 & 12.79 & 0.384 \\
& PC & 14.63 & 14.63 & 14.12 & 0.691 \\
& BG & 21.47 & 21.39 & 20.82 & 0.539 \\
& BC & 20.22 & 20.11 & 19.52 & 0.558 \\
& W & 22.16 & 22.54 & 21.07 & $\mathbf{0 . 0 5 1}$
\end{tabular}

ANOVA; statistically significant $(p \leq 0.05)$ and close-to-significant results are in bold. PC: palatal cuspid; BC: buccal cuspid; LG: lingual gingival; BG: buccal gingival (cementoenamel junction); CG: central groove; and W: Walaridge. * Statistically significant $p \leq 0.05$.

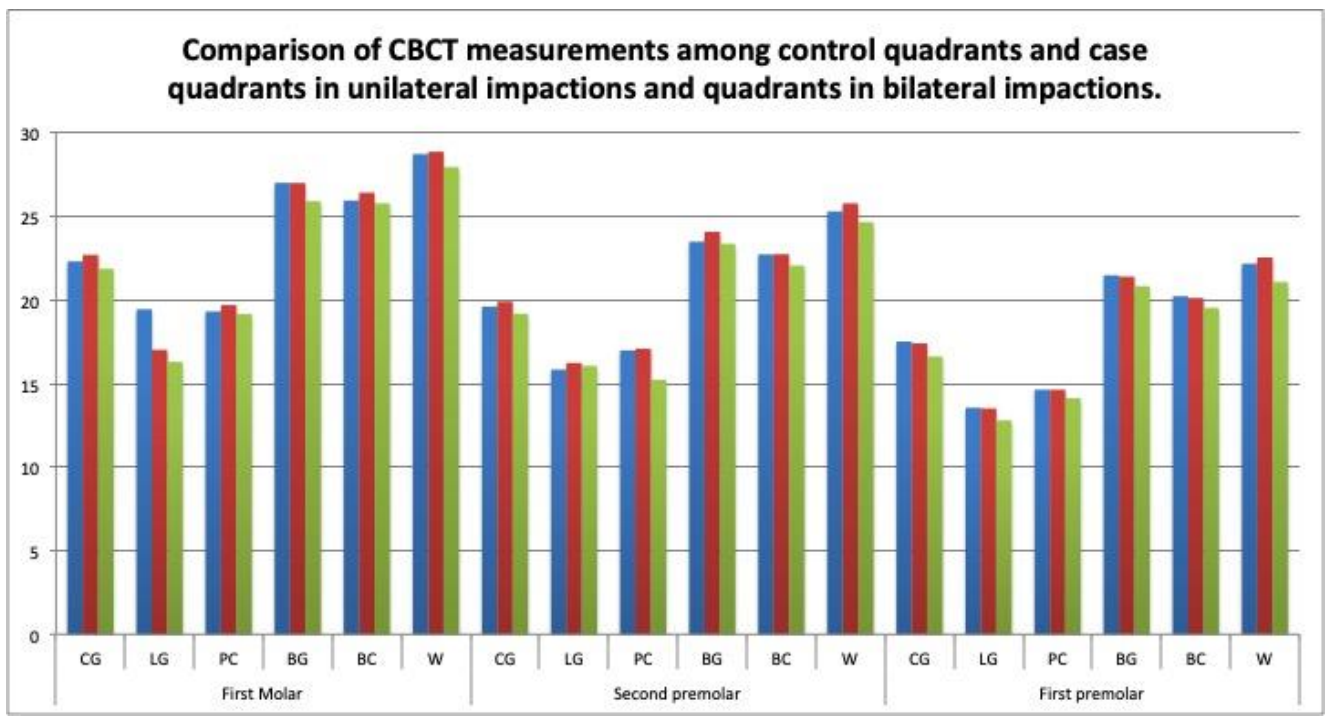

Figure 12. Comparison of CBCT measurements among control quadrants and case quadrants in unilateral impactions, and quadrants in bilateral impactions.

The total transverse widths were compared between the unilateral and bilateral cases, as they were measured on the dental casts and $\mathrm{CBCT}$ scans. On the casts, the measurements were significantly narrower in the bilateral cases at the central groove level $(37.27 \mathrm{~mm}$ vs. $39.28 \mathrm{~mm}, p=0.028)$, at the lingual gingival point $(28.62 \mathrm{~mm} v s .31 .21 \mathrm{~mm}, p=0.041)$, and at the buccal cuspid ( $41.85 \mathrm{~mm}$ vs. $45.07 \mathrm{~mm}, p=0.018)$ on the second premolars, and at the Walaridge level on the first molars (Table 7), (Figure 13). On the CBCT scans, no significant differences in the measurements were found between the bilateral and unilateral impaction groups (Table 8), (Figure 14). 
Table 7. Comparison of total transversal measurements on casts between unilateral and bilateral impactions.

\begin{tabular}{cccccc}
\hline Tooth & Parameter & $\begin{array}{c}\text { Unilateral } \\
\text { Group }\end{array}$ & $\begin{array}{c}\text { Bilateral } \\
\text { Group }\end{array}$ & $\boldsymbol{n}$ & $\boldsymbol{p}$ Value * \\
\hline \multirow{3}{*}{ First Molar } & CG & 46.18 & 44.1 & 2.08 & 0.071 \\
& GL & 32.94 & 31.29 & 1.65 & 0.120 \\
& MBC & 50.22 & 48.45 & 1.77 & 0.209 \\
Second & W & 57.44 & 54.99 & 2.45 & $\mathbf{0 . 0 5 4}^{*}$ \\
Premolar & GG & 39.98 & 37.27 & 2.71 & $\mathbf{0 . 0 2 8}^{*}$ \\
& GL & 31.21 & 28.65 & 2.59 & $\mathbf{0 . 0 4 1}^{*}$ \\
& GC & 45.07 & 41.85 & 3.23 & $\mathbf{0 . 0 1 8}^{*}$ \\
First & W & 51.81 & 48.8 & 2.95 & $\mathbf{0 . 0 6 0}$ \\
\hline Premolar & GL & 34.88 & 33 & 1.88 & 0.08 \\
& BC & 26.53 & 25.2 & 1.34 & 0.323 \\
& W & 39.97 & 37.88 & 2.09 & 0.094 \\
\hline
\end{tabular}

ANOVA; statistically significant and close-to-significant results are in bold. CG: central groove; GL: gingival lingual; MBC: mesiobuccal cuspid; BC: buccal cuspid (premolars); and W: Walaridge. * Statistically significant $p \leq 0.05$.

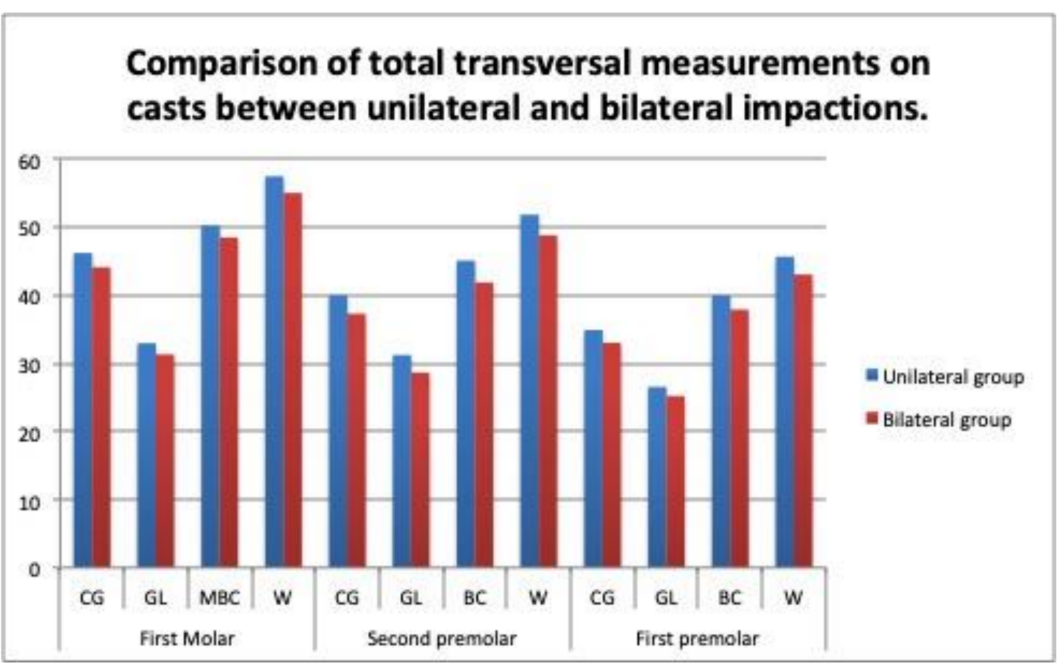

Figure 13. Comparison of total transversal measurements on casts between unilateral and bilateral impactions.

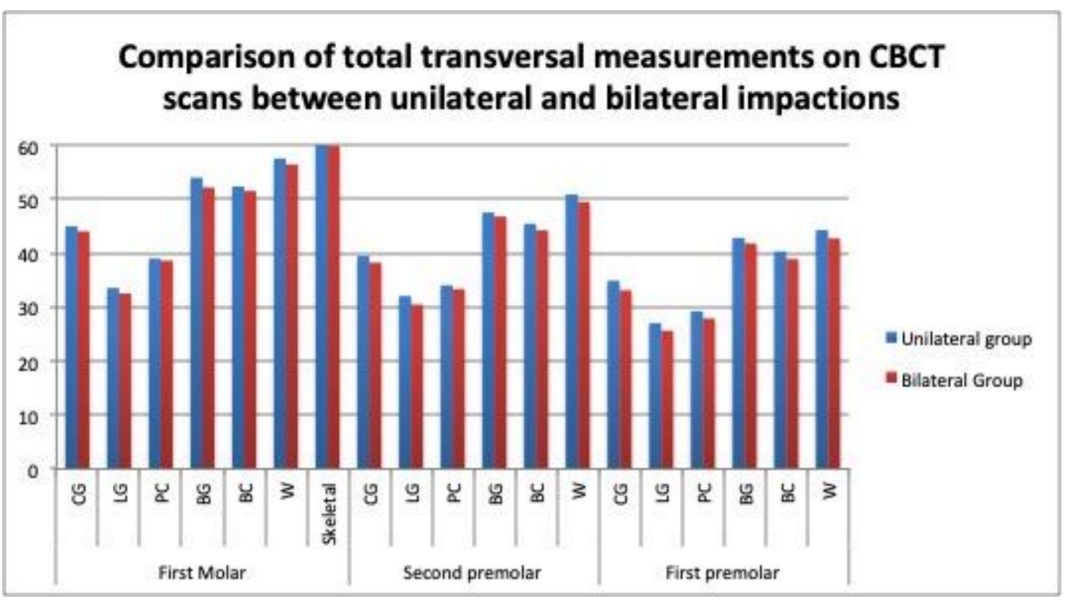

Figure 14. Comparison of total transversal measurements on CBCT scans between unilateral and bilateral impactions. 
Table 8. Comparison of total transversal measurements on CBCT scans between unilateral and bilateral impactions.

\begin{tabular}{cccccc}
\hline Tooth & Parameter & $\begin{array}{c}\text { Unilateral } \\
\text { Group }\end{array}$ & $\begin{array}{c}\text { Bilateral } \\
\text { Group }\end{array}$ & $\boldsymbol{n}$ & $\boldsymbol{p}$ Value * \\
\hline \multirow{5}{*}{ First Molar } & CG & 44.99 & 44.07 & 0.92 & 0.365 \\
& LG & 33.55 & 32.54 & 1 & 0.385 \\
& PC & 39 & 38.62 & 0.38 & 0.792 \\
& BG & 53.99 & 52.17 & 1.82 & 0.141 \\
& BC & 52.35 & 51.53 & 0.82 & 0.543 \\
& W & 57.58 & 56.44 & 1.14 & 0.497 \\
Second & Skelal & 61.12 & 59.94 & 1.19 & 0.385 \\
\hline \multirow{5}{*}{ Premolar } & CG & 39.48 & 38.25 & 1.23 & 0.391 \\
& LG & 32.06 & 30.47 & 1.59 & 0.214 \\
& PC & 34.05 & 33.35 & 0.7 & 0.596 \\
Frirst & BG & 47.55 & 46.79 & 0.76 & 0.465 \\
& BC & 45.45 & 44.23 & 1.22 & 0.298 \\
& W & 50.9 & 49.49 & 1.41 & 0.307 \\
\hline & CG & 34.91 & 33.1 & 1.81 & 0.093 \\
& LG & 27.06 & 25.64 & 1.42 & 0.306 \\
& PC & 29.26 & 27.91 & 1.35 & 0.315 \\
& BG & 42.84 & 41.82 & 1.04 & 0.622 \\
& BC & 40.33 & 38.93 & 1.4 & 0.139 \\
& W & 44.31 & 42.74 & 1.57 & 0.315
\end{tabular}

ANOVA. PC: palatal cuspid; BC: buccal cuspid; LG lingual gingival; BG: buccal gingival; CG: central groove; and $\mathrm{W}$ : Walaridge. * Statistically significant $p \leq 0.05$.

No relationship was observed between the maxillary transverse measurements and the buccal or palatal localization of the impaction on the casts or CBCT scans, neither in the unilateral nor the bilateral cases (Tables 9 and 10) (Figures 15 and 16). No correlations were observed between the digital model and the CBCT scan measurements in almost any dimension (Table 11).

Table 9. Comparison of cast measurements between buccal and palatal localizations in unilateral impactions.

\begin{tabular}{|c|c|c|c|c|c|c|c|c|c|c|}
\hline \multirow{2}{*}{ Tooth } & \multirow{2}{*}{ Parameter } & \multicolumn{3}{|c|}{ Control Quadrants } & \multicolumn{3}{|c|}{ Case Quadrants } & \multicolumn{3}{|c|}{ Total } \\
\hline & & Buccal & Palatal & $p$ Value * & Buccal & Palatal & $p$ Value * & Buccal & Palatal & $p$ Value * \\
\hline \multirow{4}{*}{ First Molar } & CG & 23.42 & 22.1 & 0.133 & 23.39 & 23.49 & 0.953 & 46.82 & 45.53 & 0.35 \\
\hline & GL & 16.75 & 16.03 & 0.235 & 16.86 & 16.47 & 0.644 & 33.62 & 32.56 & 0.389 \\
\hline & MBC & 25.65 & 24.25 & 0.188 & 25.43 & 25.03 & 0.616 & 51.09 & 49.29 & 0.229 \\
\hline & W & 29.24 & 28.09 & 0.193 & 29.3 & 28.75 & 0.441 & 57.07 & 57.6 & 0.249 \\
\hline \multirow{4}{*}{$\begin{array}{l}\text { Second } \\
\text { Premolar }\end{array}$} & CG & 20.36 & 19.8 & 0.494 & 19.95 & 19.79 & 0.828 & 39.6 & 40.32 & 0.615 \\
\hline & GL & 16 & 15.37 & 0.443 & 15.51 & 31.28 & 0.485 & 31.28 & 31.51 & 0.866 \\
\hline & $\mathrm{BC}$ & 23.01 & 22.23 & 0.343 & 22.48 & 22.47 & 0.987 & 44.7 & 45.5 & 0.583 \\
\hline & $\mathrm{W}$ & 26.54 & 25.48 & 0.2 & 26.58 & 25.73 & 0.3 & 51.21 & 53.12 & 0.23 \\
\hline \multirow{4}{*}{$\begin{array}{c}\text { First } \\
\text { Premolar }\end{array}$} & CG & 17.55 & 17.56 & 0.997 & 17.61 & 17.22 & 0.555 & 35.16 & 34.78 & 0.779 \\
\hline & GL & 13.21 & 13.33 & 0.803 & 13.25 & 13.33 & 0.906 & 26.46 & 27.24 & 0.6 \\
\hline & BC & 19.99 & 19.97 & 0.986 & 19.97 & 19.97 & 0.995 & 39.96 & 39.98 & 0.989 \\
\hline & $\mathrm{W}$ & 23.37 & 22.5 & 0.414 & 23.34 & 22.5 & 0.307 & 46.7 & 45.2 & 0.32 \\
\hline
\end{tabular}

* Student's $t$-test for independent samples. CG: central groove; GL: gingival lingual; MBC: mesiobuccal cuspid; BC: buccal cuspid (premolars); and W: Walaridge. * Statistically significant $p \leq 0.05$. 
Table 10. Comparison of CBCT measurements between buccal and palatal localizations in unilateral impactions.

\begin{tabular}{|c|c|c|c|c|c|c|c|c|c|c|}
\hline \multirow{2}{*}{ Tooth } & \multirow{2}{*}{ Parameter } & \multicolumn{3}{|c|}{ Control Quadrants } & \multicolumn{3}{|c|}{ Case Quadrants } & \multicolumn{3}{|c|}{ Total } \\
\hline & & Buccal & Palatal & $p$ Value * & Buccal & Palate & $p$ Value * & Buccal & Palatal & $p$ Value * \\
\hline \multirow{6}{*}{ First Molar } & CG & 23.02 & 22.04 & 0.135 & 22.5 & 22.75 & 0.761 & 45.53 & 44.79 & 0.556 \\
\hline & LG & 20.23 & 19.15 & 0.063 & 17.52 & 16.81 & 0.422 & 34.83 & 33.07 & 0.166 \\
\hline & PC & 20.09 & 19.02 & 0.102 & 19.42 & 19.78 & 0.646 & 39.51 & 38.81 & 0.566 \\
\hline & BG & 27.74 & 26.72 & 0.134 & 27.05 & 26.95 & 0.912 & 54.8 & 53.68 & 0.422 \\
\hline & $\mathrm{BC}$ & 26.82 & 25.61 & 0.08 & 26.72 & 26.29 & 0.631 & 53.55 & 51.991 & 0.244 \\
\hline & W & 29.45 & 28.45 & 0.223 & 29.28 & 28.7 & 0.558 & 58.73 & 57.15 & 0.347 \\
\hline \multirow{6}{*}{$\begin{array}{l}\text { Second } \\
\text { Premolar }\end{array}$} & CG & 19.84 & 19.5 & 0.612 & 20.01 & 19.84 & 0.834 & 39.86 & 39.35 & 0.701 \\
\hline & LG & 16.11 & 15.73 & 0.567 & 16.36 & 16.18 & 0.833 & 32.47 & 31.91 & 0.684 \\
\hline & PC & 16.92 & 16.99 & 0.924 & 16.8 & 17.16 & 0.66 & 33.73 & 24.16 & 0.754 \\
\hline & BG & 23.95 & 23.3 & 0.602 & 24.52 & 23.9 & 0.483 & 48.48 & 47.21 & 0.51 \\
\hline & BC & 22.93 & 22.64 & 0.682 & 22.82 & 22.69 & 0.868 & 45.76 & 45.33 & 0.75 \\
\hline & W & 26.06 & 25.01 & 0.15 & 26.57 & 25.49 & 0.091 & 52.63 & 50.51 & 0.176 \\
\hline \multirow{6}{*}{$\begin{array}{c}\text { First } \\
\text { Premolar }\end{array}$} & CG & 17.45 & 17.52 & 0.93 & 17.55 & 17.34 & 0.783 & 35.01 & 34.87 & 0.921 \\
\hline & LG & 13.41 & 13.59 & 0.841 & 13.67 & 13.44 & 0.723 & 27.09 & 27.04 & 0.972 \\
\hline & PC & 14.61 & 14.64 & 0.977 & 14.6 & 14.63 & 0.968 & 29.21 & 29.27 & 0.968 \\
\hline & BG & 21.9 & 21.31 & 0.507 & 21.62 & 21.31 & 0.713 & 43.53 & 42.62 & 0.544 \\
\hline & BC & 20.59 & 20.09 & 0.415 & 20.37 & 20.01 & 0.692 & 40.96 & 40.1 & 0.619 \\
\hline & $\mathrm{W}$ & 22.5 & 22.04 & 0.368 & 22.77 & 22.46 & 0.757 & 43.76 & 44.5 & 0.673 \\
\hline
\end{tabular}

Student's $t$-test for independent samples. CG: central groove; GL: gingival lingual; MBC: mesiobuccal cuspid; BC: buccal cuspid (premolars), and W: Walaridge. * Statistically significant $p \leq 0.05$.

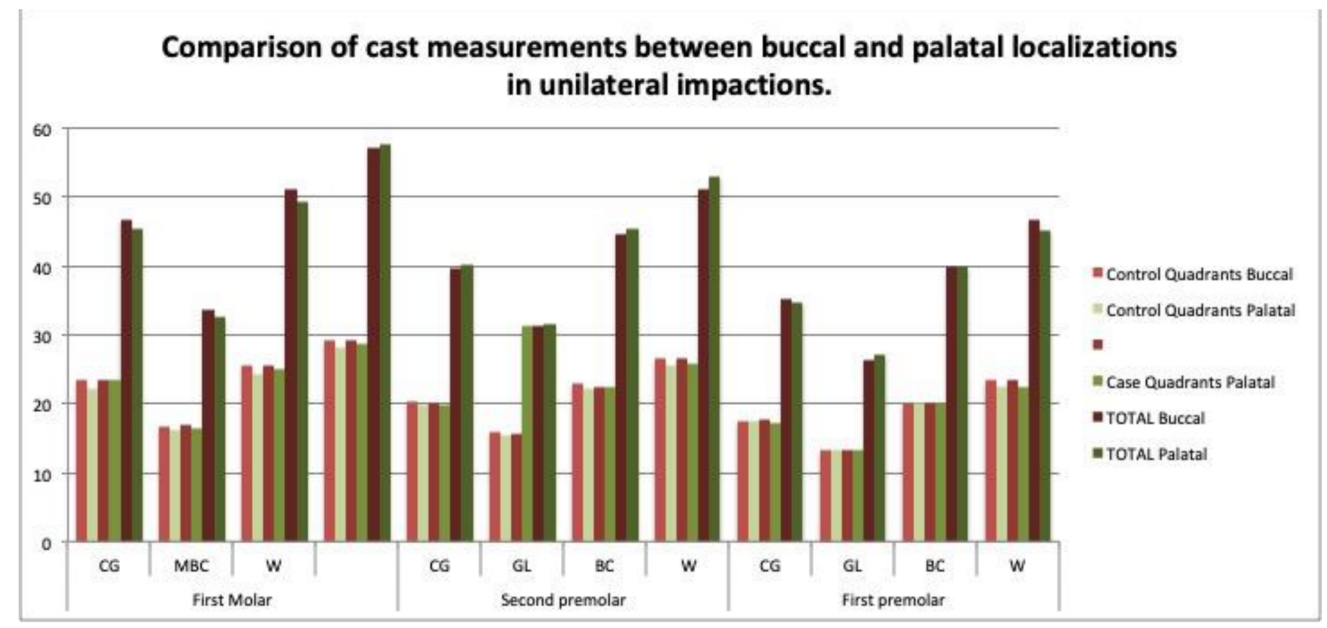

Figure 15. Comparison of cast measurements between buccal and palatal localizations in unilateral impactions. 


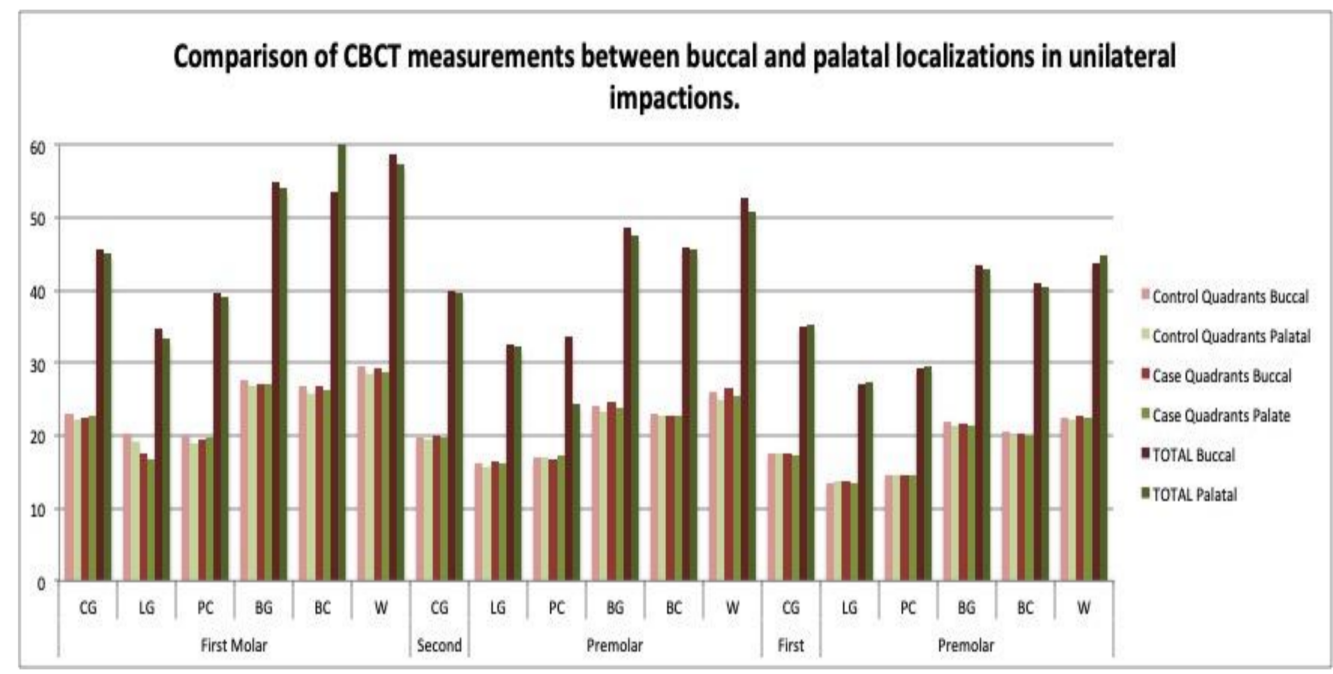

Figure 16. Comparison of $\mathrm{CBCT}$ measurements between buccal and palatal localizations in unilateral impactions.

Table 11. Comparison between digital cast and CBCT measurements.

\begin{tabular}{|c|c|c|c|c|c|c|c|c|c|c|}
\hline \multirow{2}{*}{ Tooth } & \multirow{2}{*}{ Parameter } & \multicolumn{3}{|c|}{ Control Quadrants } & \multicolumn{3}{|c|}{ Case Quadrants } & \multicolumn{3}{|c|}{ Total } \\
\hline & & Cast & CBCT & $p$ Value * & Cast & СВСТ & $p$ Value * & Cast & CBCT & $p$ Value ${ }^{*}$ \\
\hline \multirow{3}{*}{ First Molar } & CG & 22.55 & 22.37 & 0.548 & 23.28 & 22.7 & 0.041 * & 45.83 & 45.07 & $0.012 *$ \\
\hline & GL & 16.28 & 19.5 & $0.0001 *$ & 16.42 & 16.97 & $0.049 *$ & 32.7 & 33.56 & $0.001 *$ \\
\hline & $\mathrm{W}$ & 28.37 & 28.74 & $0.018^{*}$ & 28.71 & 28.86 & 0.526 & 57.07 & 57.6 & 0.018 * \\
\hline \multirow{3}{*}{$\begin{array}{l}\text { Second } \\
\text { Premolar }\end{array}$} & CG & 19.93 & 19.64 & 0.336 & 19.63 & 19.91 & 0.232 & 39.56 & 39.54 & 0.96 \\
\hline & GL & 15.53 & 15.86 & 0.251 & 15.61 & 16.27 & 0.018 * & 31.14 & 32.12 & 0.001 * \\
\hline & W & 25.66 & 25.36 & 0.001 * & 25.8 & 25.81 & 0.937 & 51.45 & 51.18 & 0.306 \\
\hline \multirow{3}{*}{$\begin{array}{c}\text { First } \\
\text { Premolar }\end{array}$} & CG & 17.46 & 17.49 & 0.883 & 17.13 & 17.22 & 0.606 & 34.59 & 34.71 & 0.406 \\
\hline & GL & 13.28 & 13.82 & 0.055 & 13.14 & 13.55 & 0.063 & 26.67 & 27.89 & 0.001 * \\
\hline & $\mathrm{W}$ & 22.78 & 22.31 & $0.026^{*}$ & 22.42 & 22.54 & 0.699 & 45.3 & 44.38 & 0.164 \\
\hline
\end{tabular}

Student's $t$-test for paired samples; statistically significant results $(p \leq 0.05)$ are in bold. CG: central groove; LG: lingual gingival; and W: Walaridge. * Statistically significant $p \leq 0.05$.

\section{Discussion}

In this study, both digital casts and $\mathrm{CBCT}$ scans were used to measure the maxillary transverse dimensions in patients with impacted canines, with the aim of evaluating the associations of the findings with the patient and impaction characteristics.

The profile of the study population was similar to that in previous investigations in terms of the buccal or palatal localization of the impactions, their unilateral or bilateral presence, and the sex distribution $[8,10,12,21-23]$. Thus, the impactions were more frequently palatal and unilateral, and there was a female:male ratio of 2:1, which is consistent with previous reports $[8,15,19]$. The maxillary dimensions are usually smaller in females than in males [16], and Hong et al. propose that the association between the impaction incidence and the female sex has a genetic origin [2,15] (Table 1) (Figure 8).

The ICC was 0.887 for all of the measurements on the CBCT scans, and almost perfect agreements were obtained at the lingual point levels on the first molars (0.961), the second premolars (0.943), and the first premolars (0.969). Other studies describe high interexaminer agreement (0.9) for the CBCT measurements [15-17], although one of these studies [17] used the cuspids on the first molars as the reference point, and their inclination or rotation could influence the results. The ICC was higher for the measurements on the casts (0.919) than for those on the CBCT scans in the present study, with the best reference point for the cast measurements being the lingual point on the first premolars (0.997), and the worst being the Walaridge on the upper first molars (0.6) (Table 2). 


\subsection{Transverse Dimensions in Case versus Control Quadrants in Unilateral Impactions}

Numerous reports have been published on this issue, but the findings have been controversial. In the present study, the measurements in the digital casts showed no significant differences in the transverse dimensions between the case and control quadrants in the unilateral impaction cases. Most of the impacted canines were palatal, and it has been widely documented that there is no relationship between palatal impaction and maxillary transverse deficiency $[8-10,12,13,15]$. Although Cacciatori et al. observed a narrower and smaller palate in impacted canine cases versus controls, they also found no significant difference between the quadrants with impacted versus nonimpacted canines in the cases of unilateral impaction [19] (Table 3), (Figure 9).

On the CBCTS scans, a statistically significant difference between the case and control quadrants was found in the measurements at the lingual level on the upper first molars and at the Walaridge level on the upper second premolars $(p<0.05)$; however, the difference at the Walaridge level was not considered because of the low interexaminer agreement on this measurement. The width at the lingual point on the upper first molars was narrower in the case (with impacted canine) $(17.01 \mathrm{~mm}$ ) versus the control quadrants $(19.44 \mathrm{~mm})$ in the unilateral impaction cases. By contrast, Misrasmaeli at al. found no statistically significant difference in this measurement at the lingual level on the upper first molars [17]. The width at the lingual level has not been measured in previous CBCT studies $[10,11,15,16]$ (Table 4), (Figure 10).

\subsection{Transverse Dimensions in Unilateral versus Bilateral Impactions by Quadrant}

On the casts, the measurements at the Walaridge point on the second premolars differed significantly between the case quadrants in the unilateral group and the quadrants in the bilateral group $(p<0.05)$. On the CBCT scans, the measurements at the lingual point on the first molars differed significantly between the case quadrants in the unilateral group and the quadrants in the bilateral group $(p<0.05)$. Our review of the literature found no study that compared the maxillary transverse measurements by quadrant between unilateral versus bilateral impactions. (Tables 5 and 6), (Figures 11 and 12).

\subsection{Transverse Dimensions in Unilateral versus Bilateral Impactions by Arch}

On the casts, the transverse measurements of the whole arch differed significantly between the patients with unilateral and bilateral impactions at the levels of the central groove, the lingual point, and the buccal cuspid on the second premolars (Table 7), (Figure 13). On the CBCT scans, no statistically significant differences were observed in any of the measurements (Table 8) (Figure 14). Mucedero and Arboleda also observed no significant differences in these dimensions between the unilateral and bilateral impactions $[14,16]$.

\subsection{Transverse Dimensions in Buccal versus Palatal Impactions}

No significant differences in the transverse dimensions were observed between the buccal and palatal impactions on either the casts or the CBCT scans (Tables 9 and 10) (Figures 15 and 16). Arboleda et al. also found no differences in the transverse dimension at the first molar level [16]. By contrast, some authors describe a significantly narrower transverse width in the premolar region in cases of buccal impaction [10], and others have found an association between canine impaction and buccal displacement [14]. Therefore, the relationship between the palatal or buccal localization of impaction and the maxillary transverse dimensions is unclear [7].

\subsection{Transverse Measurements on CBCT Scans versus Casts}

Our review of the literature was unable to trace studies that compared the transverse measurements between the digital models and the CBCT scans. In the present study, four measurement points were selected that might, theoretically, provide more similar results between the two techniques. However, there were no correlations between these approaches in the dimensions obtained at these points. In the cases of unilateral impaction, 
statistically significant differences were found in the measurements at the central groove, the lingual point, and the Walaridge levels. Hence, the measurements obtained at the selected points with one of these techniques are not comparable to those obtained by the other (Table 11).

\subsection{Clinical Relevance}

The transverse measurements made in the CBCT scans and digital models could be used in the diagnosis of patients with transverse malocclusions or included canines. However, it is important to consider that there is not an absolute correspondence between the two diagnostic methods. A differential diagnosis will indicate if expansion is needed and should focus on the dental or skeletal components, or both.

According to our results, the bilateral impaction cases may require maxillary expansion more frequently than the unilateral impaction cases, where asymmetrical expansion might be considered, and CBCT scans and digital models are valid tools for assessing this asymmetry.

\section{Limitations:}

- Taking impressions with alginate and the subsequent casting in plaster may lead to certain accuracy errors in the digital models. The use of the latest-generation intraoral scanner could possibly produce a more accurate result because of the lack of cumulative errors, as the results from the systematic review by Jedlinski et al. suggest [24].

- $\quad$ It would be worthwhile to compare the results obtained with the results obtained from intraoral scans;

- The infrabony position of the impacted canine, especially the distance to the occlusal plane, has not been considered (only its palatal or buccal position). The transversal maxillary development may be affected by this factor.

\section{Conclusions}

In terms of our main objective, we can conclude that there is no relationship between the maxillary canine impaction and the arch width measured by the quadrants at the dental, dentoalveolar, or skeletal levels. The maxillary transverse width measurements on the CBCT scans are not correlated with those on the digital casts at the central groove, lingual point, or Walaridge levels.

The secondary findings from our study are as follows:

1. The demographic data confirm that impacted canines were more frequent in females versus males, and when the impaction was palatal versus buccal, and unilateral versus bilateral. These impaction characteristics were not related to the maxillary arch width;

2. There is no relationship between the maxillary arch width and the buccal or palatal displacement of the impacted canine;

3. In the bilateral impactions, the maxillary arch had a smaller transverse width at the dental level. This difference was statistically significant on the digital casts but not on the CBCT scans;

4. In the unilateral impactions, statistically significant differences in the measurements were observed between the case and control quadrants on both the digital casts and the CBCT scans.

Author Contributions: Methodology, C.M., J.G.M., G.S.A. and E.M.M.; validation, J.G.M. and E.M.M.; investigation, J.G.M. and E.M.M.; writing-original draft preparation, E.M.M., C.M.; supervision, C.M. All authors have read and agreed to the published version of the manuscript.

Funding: This research received no external funding. This research did not receive any specific grants from the funding agencies in the public, commercial, or not-for-profit sectors. 
Institutional Review Board Statement: The study was conducted according to the guidelines of the Declaration of Helsinki and was approved by the Institutional Review Board (or Ethics Committee) of Hospital San Carlos (project 20/613; URI 33-231120/date of approval).

Informed Consent Statement: Informed consent was obtained from all the subjects involved in the study.

Data Availability Statement: Not applicable.

Acknowledgments: The authors are grateful to the patients for their cooperation in this study, and they would like to acknowledge the editorial assistance of Richard Davies, MA.

Conflicts of Interest: The authors declare no conflict of interest.

\section{References}

1. Bishara, S. Clinical Management of Impacted Maxillary Canines. Semin. Orthod. 1988, 4, 87-98. [CrossRef]

2. Becker, A. Guidance theory of palatal canine displacement. Angle Orthod. 1995, 65, 95-102. [PubMed]

3. Peck, S.; Peck, L.; Kataja, M. Concomitant occurrence of canine malposition and tooth agenesis: Evidence of orofacial genetic fields. Am. J. Orthod. Dentofac. Orthop. 2002, 122, 657-660. [CrossRef] [PubMed]

4. Bishara, S. Impacted Maxilary canines: A review. Am. J. Orthod. Dentofac. Orthop. 1992, 101, 159-171. [CrossRef]

5. Jacoby, H. The etiology of maxillary canine impactions. Am. J. Orthod. Dentofac. Orthop. 1983, 84, 125-132. [CrossRef]

6. McConnell, T.; Hoffman, D.L.; Forbes, D.P.; Janzen, E.K.; Weintrub, N.H. Maxillary canine impaction in patients with transverse maxillary deficiency. J. Dent. Child. 1996, 7, 190-195.

7. Kim, Y.; Hyun, H.-K.; Jang, K.-T. Interrelationship between the position of impacted maxillary canines and the morphology of the maxilla. Am. J. Orthod. Dentofac. Orthop. 2012, 141, 556-562. [CrossRef]

8. Langberg, B.J.; Peck, S. Adequacy of maxillary dental arch width in patients with palatally displaced canines. Am. J. Orthod. Dentofac. Orthop. 2000, 118, 220-223. [CrossRef]

9. Saiar, M.; Rebellato, J.; Sheats, R.D. Palatal displacement of canines and maxillary skeletal width. Am. J. Orthod. Dentofac. Orthop. 2006, 129, 511-519. [CrossRef]

10. Yan, B.; Sun, Z.; Fields, H.; Wang, L.; Luo, L. Etiologic factors for buccal and palatal maxillary canine impaction: A perspective based on cone-beam computed tomography analyses. Am. J. Orthod. Dentofac. Orthop. 2013, 143, 527-534. [CrossRef]

11. Tai, B.; Goonewardene, M.S.; Murray, K.; Koong, B.; Islam, S.M.S. The reliability of using postero-anterior cephalometry and cone-beam CT to determine transverse dimensions in clinical practice. Aust. Orthod. 2014, 30, 132-142.

12. Bizzarro, M.; Generali, C.; Maietta, S.; Martorelli, M.; Ferrillo, M.; Flores-Mir, C.; Perillo, L. Association between 3D palatal morphology and upper arch dimensions in buccally displaced maxillary canines early in mixed dentition. Eur. J. Orthod. 2018, 40, 592-596. [CrossRef]

13. Ghaffar, F.; Sukhia, R.H.; Fida, M. Association between maxillary transverse discrepancy and occurrence of potentially impacted maxillary canines in mixed dentition patients. Int. Orthod. 2019, 17, 554-561. [CrossRef]

14. Mucedero, M.; Rozzi, M.; Di Fusco, G.; Danessi, C.; Cozza, P. Morphometric analysis of the palatal shape and arch dimension in subjects with buccally displaced canine. Eur. J. Orthod. 2020, 42, 544-550. [CrossRef] [PubMed]

15. Hong, W.H.; Radfar, R.; Chung, C.-H. Relationship between the maxillary transverse dimension and palatally displaced canines: A cone-beam computed tomographic study. Angle Orthod. 2015, 85, 440-445. [CrossRef] [PubMed]

16. Arboleda-Ariza, N.; Schilling, J.; Arriola-Guillén, L.E.; Ruíz-Mora, G.A.; Rodríguez-Cárdenas, Y.A.; Castillo, A.A.-D. Maxillary transverse dimensions in subjects with and without impacted canines: A comparative cone-beam computed tomography study. Am. J. Orthod. Dentofac. Orthop. 2018, 154, 495-503. [CrossRef] [PubMed]

17. Miresmaeili, A.; Shokri, A.; Salemi, F.; Dehghani, F.; Shahidi-Zandi, V.; Rad, R.; Shahdoost, M. Morphology of maxilla in patients with palatally displaced canines. Int. Orthod. 2019, 17, 130-135. [CrossRef] [PubMed]

18. Zhou, N.; Guo, J. Efficiency of upper arch expansion with the Invisalign system. Angle Orthodontist 2020, 90, 23-30. [CrossRef]

19. Cacciatore, G.; Poletti, L.; Sforza, C. Early diagnosed impacted maxillary canines and the morphology of the maxilla: A three-dimensional study. Prog. Orthod. 2018, 19, 20. [CrossRef]

20. Ferrillo, M.; Curci, C.; Roccuzzo, A.; Migliario, M.; Invernizzi, M.; de Sire, A. Reliability of cervical vertebral maturation compared to hand-wrist for skeletal maturation assessment in growing subjects: A systematic review. J. Back Musculoskelet Rehabil. 2021, 34, 925-936. [CrossRef]

21. Anic-Milosevic, S.; Varga, S.; Lapter-Varga, M.; Slaj, M. Dental and occlusal features in patients with palatally displaced maxillary canines. Eur. J. Orthod. 2009, 31, 367-373. [CrossRef] [PubMed]

22. Schindel, R.H.; Duffy, S.L. Maxillary Transverse Discrepancies and Potentially Impacted Maxillary Canines in Mixed-dentition Patients. Angle Orthod. 2006, 77, 430-435. [CrossRef]

23. Naoumova, J.; Alfaro, G.E.; Peck, S. Space conditions, palatal vault height, and tooth size in patients with and without palatally displaced canines: A prospective cohort study. Angle Orthod. 2018, 2, 726-732. [CrossRef] [PubMed]

24. Jedliński, M.; Mazur, M.; Grocholewicz, K.; Janiszewska-Olszowska, J. 3D Scanners in Orthodontics-Current Knowledge and Future Perspectives-A Systematic Review. Int. J. Environ. Res. Public Health 2021, 18, 1121. [CrossRef] 